\title{
A national survey of ethnic differences in knowledge and understanding of supplementary health insurance
}

\author{
Manfred S. Green ${ }^{1 *}$, Samah Hayek ${ }^{1}$ Jalal Tarabeia ${ }^{2}$, Mohammad Yehia ${ }^{3}$ and Neta HaGani ${ }^{1}$
}

\begin{abstract}
Background: Knowledge and understanding of what health insurance covers is an important public health issue. In Israel, whereas national health insurance covers all residents, optional supplemental health insurance (SHI) can be purchased from the healthcare providers, for additional, special services. The purpose of this study was to identify disparities between Jews and Arabs in their knowledge and understanding of SHI.
\end{abstract}

Methods: National, cross-sectional, telephone survey using a structured questionnaire, among random samples of 814 Jews and 800 Arabs. Knowledge and understanding of health insurance was assessed by a score based on correct answers to 8 questions. Log-linear regression was used to estimate association between health insurance knowledge and population group, after controlling for potential confounding independent variables.

Results: Ninety one percent of Jews and $62 \%$ of Arabs reported owning SHI. Among both groups, knowledge levels were low on a 0-8 scale. However, the average score for Jews was statistically higher (Mean = 3.50, S.D = 1.69) as compared with Arabs (Mean $=2.78, S . D=1.70)(p<0.001)$. The adjusted health insurance knowledge score was significantly higher among Jews than Arabs (Prevalence ratio $=1.10 ; 95 \% \mathrm{Cl}=1.06-1.13$ ), indicating that differences remain even after controlling for socio-demographic characteristics and SHI ownership.

Conclusions: There is a large gap between the public's understanding of what is covered by SHI and the services that it covers in practice. Low SHI knowledge and understanding may lead to frustration, and limit access to additional health care among populations that suffer from socio-economic inequalities. These findings emphasize the need to provide clearer and more culturally sensitive information on health insurance coverage.

\section{Background}

Knowledge and understanding of health insurance coverage is important to exercise rights to good health care. When deciding whether to purchase health insurance, consumers struggle with calculating their costs and with medical terminology [1]. Consumers also often have difficulties in weighing complex information [2] and show limited ability to weigh the copayments against insurance premium costs [3]. Although many experience difficulties understanding and thus operating in the health insurance market, relatively little attention has been paid in the literature to

\footnotetext{
* Correspondence: manfred.s.green@gmail.com

'School of Public Health, University of Haifa, Abba Hushi 199, Haifa, Israel Full list of author information is available at the end of the article
}

knowledge and understanding of health insurance coverage [3].

National health insurance (NHI), introduced in Israel in 1995, covers a comprehensive package of medical services including primary and specialist medical consultations, medications, hospitalization and surgical procedures. It is funded through compulsory taxation and is calculated according to the level of income and social security status (salaried/self/un-employed or student). Medical services are obtained through membership in one of four health funds, which are similar in many ways to health maintenance organizations (HMO).

In addition to the basic package covered by NHI, supplementary health insurance (SHI) is offered to all members of the health funds at additional cost. It covers items such as discounts on special services not 
included in the basic package, more options for second opinions, alternative medicine, cosmetic procedures, discounts on dental care etc. There are also special plans for women, children, young/old people and families, such as treatment for childhood developmental problems and discounts on orthodontic care [4]. SHI can be purchased at several levels of comprehensiveness and costs. All members are eligible for SHI and there is no selection based on age or health status, although the costs of SHI plans increase with age. In addition to SHI provided by health funds, consumers can purchase commercial health insurance (CHI) either directly from private non-health fund related insurance companies or as groups through their workplace or through membership in professional organizations.

In spite of universal healthcare, there are inequalities between Arabs and Jews in health and health care which may be related to gaps in knowledge and utilization of supplementary health insurance. The Arab population has poorer health status compared to the Jewish population. Arabs have higher rates of heart diseases and diabetes and lower life expectancy $[5,6]$. In addition, the Arab population is characterized by lower education and income and, larger families and tend to reside in peripheral areas where the access to health professionals and services are lower [7]. Together with language and cultural barriers, all of these factors may contribute to inequalities in health [8].

In $2009,81 \%$ of the adult population in Israel was insured by some kind of additional health insurance (i.e. either SHI or CHI). This rate was lower among Arab-speakers (63\%) and low-income groups (66\%). Thirty five percent reported they had CHI [9].

In efforts to promote accessibility to information about services and rights, the Ministry of Health $(\mathrm{MOH})$ operates a website with information regarding SHI. In addition, in 2011, the $\mathrm{MOH}$ established a telephone service center which provides information in 5 languages on matters such as: rights in the health system and the National Health Insurance Law [10].

While efforts are being made to provide the public with information on SHI coverage, it is not clear to what extent various segments of the population understand what additional services are included and whether they actually need them. If they fail to understand the kind of services provided by SHI, this could lead to a number of consequences. Firstly, there may be excessive outlays for insurance for services they do not need. Secondly, there may be disappointment resulting from the gap between the expected and actual services covered by SHI. Thirdly, there may be under-insurance for services needed. Finally, there may be underutilization of the services provided by SHI when needed, due to lack of understanding of the services covered by the insurance [11]. In Israel, there is a paucity of data on the extent to which the population understands the coverage provided by SHI. Moreover, health insurance knowledge may differ between the Arab and Jewish population groups due to cultural and language differences.

The overall objective of this study was to compare the knowledge and understanding of a number of components of SHI between Israeli Arabs and Jews. The subjects studied were coverage for private nursing, choice of physician, second opinion, private room in the hospital, reduced waiting times, lower out-of-pocket expenses, catastrophic illnesses, treatment abroad, transplants, special diagnostic tests and in general, higher availability of services.

\section{Methods}

The study was carried out in two phases. In the first phase, six focus groups were conducted, each comprising six to eight men and women, three in each of the Jewish and Arab populations. The members of the focus groups were recruited from the general population and participants were asked in-depth questions about their understanding and expectations from SHI. The questions and responses were recorded and the transcript summarized into major categories and themes. These were used to finalize the contents of the questionnaire.

The second phase of this study comprised two population-based cross-sectional telephone surveys. The sampling frame comprised of the adult (age 25-75) Arab and Jewish population in Israel. The sampling was random and those who were unable to complete a telephone interview were excluded from the study. The surveys were conducted by a survey company, using trained interviewers and random digit dialing. Unanswered numbers were removed from the sample frame after 8 attempts. Each interview lasted about $10 \mathrm{~min}$. Quality control procedures were implemented at all levels of data collection (training of staff, re-interviewing a sub-sample), data entry and data analysis. In total, 1614 full interviews and 158 partial interviews were conducted, 149 of those contacted found it difficult to respond and 868 refused to participate.

The justification of the sample size is as follows: For the prevalence estimates, such as ownership of SHI, and expectations from the services provided by $\mathrm{SHI}$, the sample sizes were selected to obtain precision based on $95 \%$ confidence intervals of $\pm 4 \%$, allowing for an expected percentage of $60 \%$ for SHI ownership, yields sample sizes of about 550 in each group. For the comparison of prevalence between sub-groups, the sample sizes were chosen to detect differences between the groups of at least $5 \%$ in the prevalence of estimates for variables such as ownership of SHI and expectations from SHI, with alpha chosen to be $5 \%$ and a statistical power of $80 \%$. This required sample sizes of about 500 
in each group. For multivariate analyses the sample sizes needed to be increased to account for the additional variables in the analyses. Thus the sample sizes were increased to 800 in each group.

The questionnaires covered four areas: 1) SHI knowledge 2) behaviors and utilization of SHI 3) attitudes and expectations from SHI services 4) reasons for purchasing SHI. The questionnaires were translated into Hebrew, Arabic and Russian and back-translated, and tested in the respective communities on samples of about 20 people from the target populations. The questionnaires were tested for face, content and consensual validity, for retest reliability (correlations) and internal consistency (Cronbach's alpha). The final questionnaire is attached in Additional file 1.

For the questionnaire survey, the main dependent variable was knowledge of health insurance based on a score from the sum of the correct answers to 8 questions $(1=$ true, $0=$ not true/don't know) on services that may or may not be covered by SHI such as: "private room in a hospital", consultation with a specialist, medications not included in the standard basket of services (items 16-23), generating a summary score ranging from 0 to $8(\alpha=0.75)$. Other dependent variables were based on an average score on a 1-5 Likert scale $(1=$ do not agree, $5=$ very much agree) and included: considerations for purchasing SHI (items 1013) $(\alpha=0.57)$, ways of obtaining knowledge of health related issues such as: health insurance, disease prevention and treatment (items 39-43) $(\alpha=0.60)$ and frequency of obtaining knowledge about SHI (item 44). Participants were also asked about reasons for not purchasing SHI (item 3).

The main independent variable was population group (Jews, Arabs). Potential confounding variables included age, sex, education (primary, secondary, technical and academic), socioeconomic status-SES (based on family income), health fund membership (one of four possible health funds), health status (self-reported on a Likert scale 1-5) and occupation (salaried or self-employed).

Standard univariate analyses were conducted to describe the characteristics of the study population by socio-demographic and other relevant descriptive variables. The normal approximation was used to provide relevant confidence intervals (CIs). In order to assess the factors associated with the SHI knowledge score, we used log-linear regression with negative binomial distribution to adjust for the over dispersed answers. Prevalence ratios (PR) were computed with 95\% CIs. All the statistical analyses were conducted using SAS (version 9.3. Cary, NC: SAS Institute Inc; 2011).

\section{Results}

The characteristics of the study sample are given in Table 1. There were more women than men in both groups. Compared to the Jewish respondents, Arab respondents were younger (mean age 47.0 vs. 50.6), with less education, more children per family, lower household income, more likely to be married and had poorer self-reported health status. There were similarities between the two groups in prevalence of chronic disease and chronic use of medications (Table 1). In general, characteristics of each sample by gender, age, and education, were similar to their proportion among each population group in Israel [12].

\section{SHI ownership, costs and utilization}

Ninety one percent of the Jews in the sample reported owning SHI as compared with $62 \%$ of the Arabs. In addition, $35 \%$ of the Jews and $52.5 \%$ of the Arabs declared that they had either never used or had no recollection of using their SHI. In Fig. 1 the distribution of SHI ownership is shown by age and ethnic group. About $28 \%$ of Jews and 39\% of Arabs considered the outlay for SHI to be a significant part of household expenses. The average cost for SHI estimated by Jews was 247 NIS per month whereas Arabs estimated it at 200 NIS per month. About $40 \%$ of Jews and $56 \%$ of Arabs believed that SHI cost less than 200 NIS per month. Among the main reasons for not purchasing SHI were: high costs $(28 \%)$ and having $\mathrm{NHI}$ providing all necessary services (27\%). Only $7 \%$ reported having $\mathrm{CHI}$ as a reason for not purchasing SHI (Data is not shown in a table).

\section{Reasons for purchasing SHI}

There were no significant differences between Jews and Arabs in the average score (1-5 Likert scale, $1=$ do not agree; $5=$ very much agree) of purchasing SHI due to better high standard treatment $(3.43$ vs. 3.50, respectively), fear from catastrophic illnesses not covered by the NHI ( 3.65 vs. 3.75 , respectively), and subsidized medications and treatments (3.81 vs. 3.95). However, there were significant differences between Jews and Arabs in the average score of purchasing SHI due to shorter waiting list (2.66 vs. 3.02, respectively) (Data is not shown in a table).

\section{Knowledge about SHI}

Knowledge about SHI is shown in Table 2. Participants were presented with different health care services and were asked to identify which services they think are included in SHI coverage. Items were scored dichotomously as correct, incorrect or "don't know".

Regarding some of the services, a large percentage of participants reported they "don't know" if they are included in SHI. For example, many of the Arabs (48\%) and the Jews (44\%) didn't know that SHI subsidize services such as a private nurse during hospitalization and do not cover fully other services such as physiotherapy (37\% Arabs and 35\% Jews). Many Arabs (43\%) and Jews 
Table 1 Ethnic difference in demographic characteristics of the study population

\begin{tabular}{|c|c|c|c|c|}
\hline & & Arabs & Jews & $P$ value \\
\hline & & $(N=800)$ & $(N=814)$ & \\
\hline & & $\mathrm{n}, \%$ & $\mathrm{n}, \%$ & \\
\hline Age (years) & Mean (STD) & $47.0(11.9)$ & $50.6(12.5)$ & $P<0.001$ \\
\hline & Min-Max & {$[25-75]$} & {$[25-75]$} & \\
\hline Gender & & & & $P=0.853$ \\
\hline & Males & $358(44.8 \%)$ & $368(45.2 \%)$ & \\
\hline & Females & $442(55.2 \%)$ & $446(54.8 \%)$ & \\
\hline Marital status & & & & $P<0.001$ \\
\hline & $\begin{array}{l}\text { Single/Divorced/Separated/ } \\
\text { Single parent/Widow }\end{array}$ & $103(12.9 \%)$ & $137(16.9 \%)$ & \\
\hline & Married/live with a partner & $696(87.1 \%)$ & $674(83.1 \%)$ & \\
\hline Number of children & Mean (STD) & $1.56(1.6)$ & $1.44(1.8)$ & $P=0.169$ \\
\hline Tess than 18 years & [Min-Max] & {$[0-10]$} & {$[0-10]$} & \\
\hline Employment & & & & $P<0.001$ \\
\hline & Salaried & $362(45.4 \%)$ & $512(63.0 \%)$ & \\
\hline & Self employed & $90(11.3 \%)$ & $89(11.0 \%)$ & \\
\hline & Pensioner & $64(8.0 \%)$ & $106(13.0 \%)$ & \\
\hline & Other ${ }^{a}$ & $282(35.3 \%)$ & $105(12.9 \%)$ & \\
\hline Household income & & & & \\
\hline & Below average & 405 (53.4\%) & $211(30.9 \%)$ & \\
\hline & Average & $196(25.8 \%)$ & $166(24.3 \%)$ & \\
\hline & Above average & $158(20.8 \%)$ & $305(44.7 \%)$ & \\
\hline Education & & & & $P<0.001$ \\
\hline & Less than high school & $325(50.0 \%)$ & $103(12.8 \%)$ & \\
\hline & High school -matriculation & $151(19.0 \%)$ & $116(14.4 \%)$ & \\
\hline & Academic & $269(33.9 \%)$ & $454(56.3 \%)$ & \\
\hline & Professional and others & $48(6.0 \%)$ & $134(16.6 \%)$ & \\
\hline Chronic disease & & & & $P=0.801$ \\
\hline & Yes & $219(27.4 \%)$ & $224(28.0 \%)$ & \\
\hline & No & $580(72.6 \%)$ & 577 (72.0\%) & \\
\hline Medication & & & & $P<0.001$ \\
\hline & Yes & 307 (38.4\%) & $328(40.7 \%)$ & \\
\hline & No & $492(61.6 \%)$ & 477 (59.2\%) & \\
\hline Overall health status & & & & $P<0.001$ \\
\hline & Bad & 57 (7.2\%) & $37(4.6 \%)$ & \\
\hline & Good & 159 (20.0\%) & $112(14.0 \%)$ & \\
\hline & Very Good & 577 (72.8\%) & $651(81.4)$ & \\
\hline Owning SHI & & & & \\
\hline & Yes & 497(62.1\%) & 743(91.3\%) & $P<0.001$ \\
\hline & No & 303(37.9\%) & $71(8.7 \%)$ & \\
\hline
\end{tabular}

a"Other" Include: Stay at home parents, students and unemployed

(42\%) did not know that SHI does not cover cancer medications not included in the basket of services covered by NHI because SHI does not cover treatment for life threatening illnesses.
In addition, many participants wrongly indicated certain services as included in SHI when they were not. For example: most of the participants presumed that SHI gives them the option to select a surgeon or physician of 


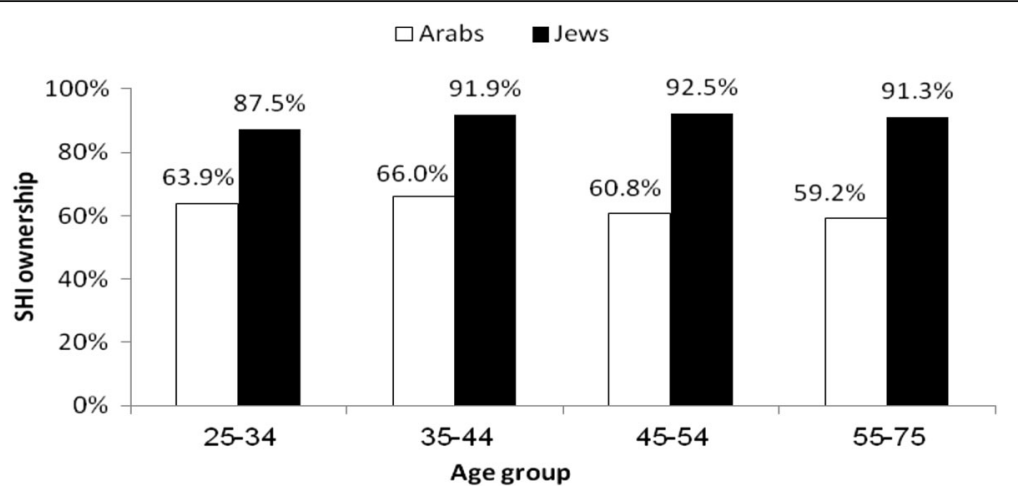

Fig. 1 Percent of SHI owners by ethnic group and age

one's choice from anywhere in the country (46\% Arabs and 57\% Jews), although SHI only offers a limited choice of doctors/surgeons from a list provided by the health fund [13].

The differences between Jews and Arabs were both in knowledge about services that are partially covered such as consultation with a specialist (44\% for Arabs and $83 \%$ for Jews) and about services that are not covered such as full coverage for physiotherapy (31\% for Arabs and 22\% for Jews) and having a private room during hospitalization (18\% for Arabs and 10\% for Jews). For prenatal care, the knowledge was similar between the two groups, whereas for subsidized surgery abroad, there was slightly less knowledge among Arabs (see Table 2). Overall, the scores for knowledge were lower for Arabs than for Jews $(2.78$ vs. 3.49, $p<0.001)$ (Data is not shown in a table).

The results of the multivariate regression analyses are shown in Table 3 . Jews had a significantly high score for health insurance knowledge $(\mathrm{PR}=1.12$; CI 1.06-1.13) after controlling for potential confounders. In order to assess whether ownership of SHI affected the difference in the health insurance knowledge score between Jews and Arabs, we carried out further regression analyses (Table 3). After controlling for ownership of SHI, The PR changed from 1.12 to 1.10 which was still statistically significant (PR = 1.10; CI 1.06-1.13, $p<0.001)$.

\section{Attempts to learn about SHI}

More than $50 \%$ of both Arabs and Jews reported that they lacked information on SHI.

A large percentage did not investigate what SHI covers before purchasing it (36\% among Jews and 32\% among Arabs). About a third of participant (32\%) reported they don't know at all what their monthly cost of SHI is and relatively few reported that they knew exactly what it cost (19\%).

Among Jews, friends/family and the internet/social media were rated as most important for obtaining knowledge regarding health related issues (such as: health insurance, disease prevention and treatment). Among Arabs, healthcare professionals (doctors/ nurses) and television/radio were the most important for obtaining knowledge. Overall, among both Arabs and Jews, a high percentage, rarely or never try to learn about the coverage of SHI (72\% vs. 67\%) (Data is not shown in a table).

\section{Discussion}

The current study examined differences in SHI knowledge and understanding between two population groups in Israel- Arabs and Jews. Findings show that overall, owning SHI was substantially higher among Jews. In general, about a third of both groups did not investigate what SHI covers before purchasing it and relatively few knew exactly what it cost. There were misconceptions about what SHI covers and about the need for SHI for general health care. After controlling for selected confounding variables, such as socio-demographic variables (gender, age and education) and SHI ownership, differences between Arabs and Jews in SHI knowledge and understanding persist.

SHI knowledge was lower among Arabs compared to Jews, when measured by objective measures, as well as by participants' subjective self-reports about their lack of knowledge. The lower SHI knowledge found among Arabs coincides with lower rates of SHI ownership and lower SES, as well as with previous research, suggesting lower levels of knowledge and awareness to health related issues is a result of socioeconomic gaps [14].

The lower scores in SHI knowledge among Arabs may be a marker of less efficient use of healthcare services. In a study conducted in the United States, the authors pointed out that each person must understand and select the most appropriate plan, while understanding which services are and are not covered [14]. In a systematic review, beneficiaries' knowledge of the United States optional Part D program for Medicaid was poor, particularly with regards 
Table 2 Familiarity with SHI according to knowledge about Services that are included or not included in SHI

\begin{tabular}{|c|c|c|c|c|c|}
\hline \multirow{3}{*}{ Subsidized Private Nurse in hospitalization after surgery } & \multicolumn{2}{|c|}{ Arabs (800) } & \multicolumn{2}{|c|}{ Jews (814) } & \multirow[t]{2}{*}{$P$ value $^{1}$} \\
\hline & $n, \%$ & & $n, \%$ & & \\
\hline & & & & & $P=0.996$ \\
\hline Included ${ }^{a}$ & 189 & 23.7 & 192 & 23.7 & \\
\hline Not Included & 226 & 28.3 & 259 & 31.9 & \\
\hline Don't know & 383 & 48.0 & 360 & 44.4 & \\
\hline Choosing a doctor or a surgeon from every hospital in Israel & & & & & $P=0.780$ \\
\hline Included & 375 & 46.9 & 465 & 57.3 & \\
\hline Not included ${ }^{a}$ & 175 & 21.9 & 173 & 21.3 & \\
\hline Don't know & 249 & 31.2 & 173 & 21.3 & \\
\hline Subsidized private prenatal care and fertility treatments & & & & & $P=0.628$ \\
\hline Included ${ }^{a}$ & 386 & 48.3 & 373 & 47.0 & \\
\hline Not included & 122 & 15.3 & 82 & 10.3 & \\
\hline Don't know & 292 & 36.5 & 338 & 42.6 & \\
\hline Subsidized transplants and surgeries abroad & & & & & $P=0.010$ \\
\hline Included ${ }^{\mathrm{a}}$ & 357 & 44.7 & 413 & 51.1 & \\
\hline Not included & 165 & 20.7 & 191 & 23.6 & \\
\hline Don't know & 277 & 34.7 & 205 & 25.3 & \\
\hline Private room in different hospitals in Israel & & & & & $P<0.001$ \\
\hline Included & 146 & 18.3 & 78 & 9.7 & \\
\hline Not included ${ }^{a}$ & 329 & 41.2 & 466 & 57.8 & \\
\hline Don't know & 324 & 40.6 & 262 & 32.5 & \\
\hline Cancer Medications not covered by basic health insurance & & & & & $P=0.196$ \\
\hline Included & 269 & 33.7 & 257 & 31.8 & \\
\hline Not included ${ }^{a}$ & 190 & 23.8 & 215 & 26.6 & \\
\hline Don't know & 339 & 42.5 & 336 & 41.6 & \\
\hline Partial coverage of Consultation with a specialist & & & & & $P<0.001$ \\
\hline Included ${ }^{a}$ & 350 & 43.9 & 670 & 82.8 & \\
\hline Not included & 188 & 23.6 & 50 & 6.2 & \\
\hline Don't know & 259 & 32.5 & 89 & 11.0 & \\
\hline Full coverage of Private physiotherapy & & & & & $P<0.001$ \\
\hline Included & 247 & 31.2 & 178 & 22.1 & \\
\hline Not included ${ }^{a}$ & 250 & 31.6 & 346 & 43.0 & \\
\hline Don't know & 295 & 37.2 & 281 & 34.9 & \\
\hline
\end{tabular}

${ }^{a}$ Correct answer

' $p$-value was calculated for incorrect answer together with "don't know" in comparison with correct answers

to the coverage gap and the low-income subsidy [15], and it has been found that consumers tend to make decisions on the basis of anecdotal information such as their friends' experiences [16]. There is evidence that this type of information can result in a biased selection of SHI [17].

The gaps found in the current study between Arabs and Jews in knowledge and understanding of SHI may be due, in part, to the cultural differences between the two population groups. Arabs in Israel are just one of the groups that are in risk to have low level of knowledge and understanding of health insurance. Others could include the elderly and other ethnic minorities [18-20]. While low level knowledge and understanding in SHI may lead to difficulties in operating in the insurance market, these difficulties can cause frustration and disappointment (for example, from unanticipated out of pocket expenses) and to lack of use and exposure to health care services, which then reinforce the low health insurance knowledge and understanding.

In the current study, among the sample of Jews, respondents reported obtaining most of their information on medical issues, including SHI, on the internet. In the 
Table 3 Estimates of the prevalence ratios for the association between Ethnicity and Supplementary Health Insurance knowledge score - Results of the Log linear regression (Negative-Binomial Regression)

\begin{tabular}{|c|c|c|c|}
\hline & & PR $(95 \% \mathrm{Cl})$ & P \\
\hline \multicolumn{4}{|l|}{ Ethnicity } \\
\hline & Jews vs. Arabs & $1.10(1.06-1.13)$ & $P<0.001$ \\
\hline Age & & $0.99(0.94-0.99)$ & $P<0.001$ \\
\hline Gender & Females vs. Males & $0.96(0.94-0.99)$ & $P=0.003$ \\
\hline \multirow[t]{4}{*}{ Education } & & & $P<0.001$ \\
\hline & $\begin{array}{l}\text { Less equal } \\
\text { high school } \\
\text { vs. professional }\end{array}$ & $0.93(0.88-0.98)$ & $P=0.012$ \\
\hline & $\begin{array}{l}\text { High school- } \\
\text { matriculation } \\
\text { vs. professional }\end{array}$ & $1.04(0.98-1.11)$ & $P=0.161$ \\
\hline & $\begin{array}{l}\text { Academic degree } \\
\text { vs. professional }\end{array}$ & $1.12(1.07-1.20)$ & $P<0.001$ \\
\hline \multirow[t]{4}{*}{ Job } & & & $P=0.410$ \\
\hline & $\begin{array}{l}\text { Employed vs. } \\
\text { not in labor } \\
\text { force }\end{array}$ & $1.01(0.96-1.06)$ & $P=0.838$ \\
\hline & Self employed & $0.99(0.92-1.07)$ & $P=0.453$ \\
\hline & Pensioner & $1.05(0.97-1.14)$ & $P=0.153$ \\
\hline \multirow[t]{2}{*}{ Marital status } & & & $P=0.439$ \\
\hline & Married vs. single & $1.03(0.98-1.07)$ & \\
\hline $\begin{array}{l}\text { Number of children } \\
\text { less than } 18 \text { yrs. Old }\end{array}$ & & $1.02(0.99-1.03)$ & $P=0.051$ \\
\hline Chronic disease & Yes vs. No & $1.03(0.99-1.07)$ & $P=0.120$ \\
\hline Medication & Yes vs. No & $0.99(0.95-1.03)$ & $P=0.670$ \\
\hline Owning SHI & Yes vs. No & $1.10(1.06-1.15)$ & $P<0.001$ \\
\hline
\end{tabular}

sample of Arabs, respondents reported obtaining most of the information from physicians or television and radio. Since most of the information today is received online and since doctors are limited in the amount of time they can spend with patients, those not using the internet may get a restricted view of the services and treatments suitable to their medical needs. On the other hand, information available online can be overwhelming and sometimes misleading. This might lead to wrong assumptions and expectations.

The success of the health insurance market depends greatly on consumers' ability to understand SHI and to make informed decisions [21, 22]. Thus, health insurance knowledge and understanding depends on obtaining valid and accurate information. Our findings show that both Arabs and Jews expected full coverage for services that had only partial coverage, such as surgical operations abroad, choosing a specialist or a surgeon and consultation with a specialist. It seems that the low level of SHI knowledge had an effect on expectations by creating confusion regarding different services and the insurance co-payments. Apart from low level of knowledge, another possible explanation of these high expectations is the aggressive marketing by $\mathrm{SHI}$ and commercial insurance companies, while trying to recruit new costumers.

These findings may also reflect socio-cultural differences between the two ethnic groups and suggest the importance of providing services adapted to different population groups. It also suggests that lack of familiarity with SHI services may influence preferences and expectations from SHI.

Our findings also show that $35 \%$ of the Jews and $52.5 \%$ of the Arabs who had SHI, declared that they had either never used or had no recollection of using SHI. The gaps found in utility of SHI between Arabs and Jews may reflect the gaps in SHI knowledge and understanding. These findings are in accordance with previous literature about the relationship between lack of utility and lack of knowledge and understanding of health insurance [23].

The current research shows that in the Israeli SHI market, consumers' behavior isn't necessarily rational, partly because it isn't based on a complete understanding of SHI. Regardless of the socio-economic gaps between Arabs and Jews, both population groups had high expectations and low knowledge and understanding regarding $\mathrm{SHI}$ services. Consumers were expecting to receive coverage for more services than SHI covers in practice.

The information from the current study can assist in identifying some of the barriers and contributing factors to knowledge and understanding of supplemental health insurance among populations at risk and provide information regarding groups that will benefit from support in their decision on purchasing SHI or operating it.

Tools for measuring health insurance literacy have recently been reported $[19,21]$ and this is an important area for future research.

\section{Potential limitations of the study}

The samples for the population survey were selected at random. However, the use of random digit dialing restricted the results of the surveys to those with land lines resulting in selection bias. This does not seem to be differentially associated with the measures of SHI knowledge and understanding between Arabs and Jews. However, this factor should be borne in mind when considering the generalizability of the findings. Since the data is based on self-reports, there may be information bias. However, there is no reason to believe that the size of the bias would be differentially distributed between the variables in any of the dependent-independent variable association examined. Thus, there may be an attenuation of the associations detected. While the most likely confounding variables were controlled in multiple regression analysis, there may be residual confounding 
or information bias in the confounding variables that remained uncontrolled.

\section{Conclusions}

This study demonstrates poor knowledge and understanding of the services offered by SHI in the whole Israeli population. We provide information regarding groups who should benefit from additional support and guidance while making decisions about purchasing SHI. One way to provide information and education is through general practitioners and nurses employed by the health providers. The gaps between Arabs and Jews in SHI knowledge and understanding imply that the type of information and the way it is disseminated should be adapted to different population groups.

\section{Additional file}

Additional file 1: Health Insurance Questionnaire. (DOC 109 kb)

\section{Abbreviations}

$\mathrm{CHI}$ : Commercial Health Insurance; Cl: Confidence intervals; $\mathrm{HMO}$ : Health Maintenance Organization; MOH: Ministry of Health; NGO: Non Governmental Organization; NHI: National Health Insurance; NIS: New Israeli Shekels; SES: Social Economic Status; SHI: Supplemental Health Insurance

\section{Acknowledgement}

There are no contributions other than the authors.

\section{Funding}

This work was supported by a grant from the National Institute for Health Policy and Research (Grant no.2012/155/א), The Sheba Medical Center, (Gertner Building), Tel Hashomer 52621, Israel. Phone: +972-3-5303516/7, Fax: +972-35303250. Email: nihp-r@israelhpr.health.gov.il Web site: www.israelhpr.org.il.

\section{Availability of data and materials}

The dataset supporting the conclusions of this article is not available for publishing.

\begin{abstract}
Authors' contributions
All authors participated in the manuscript preparation and contributed to the conception and design of the study. The specific contributions were as follows: MSG was responsible for study conception and design and directed the analyses and writing of the manuscript. SH performed the data analyses and drafting of the manuscript. JT conceived of the study and participated in drafting of the manuscript. MY conceived of the study and participated in drafting of the manuscript. NH carried out the data collection, data analyses and participated in drafting of the manuscript. All authors read and approved the final manuscript.
\end{abstract}

\section{Authors' information}

Manfred S. Green is a Professor in the Department of Epidemiology and the Director of the Global Health Leadership \& Administration Program, School of Public Health, University of Haifa. He is also adjunct Professor in College of Public Health, University of Georgia. His Research interests include: The epidemiology of chronic diseases, emerging infectious diseases and health policy. He has published more than 200 papers in peer-reviewed journals and several chapters in textbooks.

Samah Hayek, DrPH, MPH works as a researcher at the Israeli Center for Disease Control. In 2010, she received the Fulbright scholarship and earned her DrPH in Epidemiology from the University of Kentucky. In 2012, she received an evaluation fellowship from the United States CDC, where she worked in the Division of HIV/AIDS prevention.

Dr. Jalal Tarabeia is the Head Nurse of the Infection Control Unit in Tel-Aviv Medical Center and a Senior lecturer in the faculty of nursing, The Yezreel Valley
College, Affola. As a specialist in infection control and hospital epidemiology he is interested in studying risk factors for nosocomial infections, epidemiological investigation of infection outbreaks, compliance of health workers for hand hygiene and immunization against influenza. Other field of interest is the study of the health status of the Arab minority in Israel on chronic diseases and health services.

Dr. Mohammad Yehia is the founder of the Triangle R\&D center in 1999, a regional R\&D center sponsored by the Ministry of Science. Today he serves as the main researcher at the center in the field of health and history of science. Neta HaGani is a Masters candidate in clinical social work, University of Haifa. She is a research coordinator in the School of Public Health and in the School of Social Work, University of Haifa. Her main interests include: Mental health, physical and mental disabilities and health policy.

\section{Competing interests}

This paper has not been published elsewhere, nor has it been submitted for publication to any other journal. We have no relationships that might lead to competing interests.

\section{Ethics approval and consent to participate}

This study was approved by the University of Haifa, Faculty of Social Welfare \& Health Sciences Ethics Committee for Research Involving Humans, for meeting the requirements of an ethical research (Permit no. 039-13).

\section{Author details}

${ }^{1}$ School of Public Health, University of Haifa, Abba Hushi 199, Haifa, Israel. ${ }^{2}$ Faculty of Nursing, The Yezreel Valley College, Afula, Israel. ${ }^{3}$ Triangle Research and Development Center, Kfar Kara, Israel.

Received: 19 January 2016 Accepted: 13 February 2017

Published online: 07 March 2017

\section{References}

1. Greene J, Peters E. Medicaid consumers and informed decision-making. Health Care Financ R. 2009;30:25-40.

2. Wood S, Hanoch Y, Barnes A, Liu PJ, Cummings J, Bhattacharya C, Rice T. Numeracy and Medicare Part D: the importance of choice and literacy for numbers in optimizing decision making for Medicare's prescription drug program. Psychol Aging. 2011;26(2):295.

3. Tennyson S. Consumers' insurance literacy: Evidence from survey data. Financ Serv Rev. 2011:20(3):165.

4. Clalit Health Services. Complementary Health Insurance. 2012. http://www. clalit-global.co.il/en/clalit_mushlam_html. Accessed 23 Feb 2017.

5. Horev T. Decreasing inequality in health: Implementation of the international experience in Israel. Jerusalem: Taub Center for Research of Social Policy in Israel; 2008 (In Hebrew).

6. Epstein $L$. The existence of inequalities in health and health services in Israel, Inequalities in health in Israel. 2008. p. 141-50.

7. Elnekave $\mathrm{E}$, Gross R. The healthcare experiences of Arab Israeli women in a reformed healthcare system. Health Policy. 2004;69(1):101-16.

8. Epstein L, Horev T. Inequality in health and in health systems: Presentation of the problem and guidelines for policy to address it. Jerusalem: Taub Center for Research of Social Policy in Israel; 2007. In Hebrew.

9. Brammli-Greenberg S, Gross R, Yair Y, Akiva E. Public opinion on the level of service and performance of the healthcare system in 2009 and in comparison with previous years. Jerusalem: Myers - JDC - Brookdale Institute; 2011.

10. State of Israel ministry of health. Health Voice- the Ministry of Health's telephone service center. http://www.health.gov.il/English/Public_Enquiries/ Pages/CallCenter.aspx. Accessed 23 Feb 2017.

11. Kim J, Braun B, Williams AD. Understanding health insurance literacy: A literature review. Fam Consum Sci Res J. 2013;42(1):3-13.

12. Israel CBS annual data 2015. http://www.cbs.gov.il/reader/shnaton/shnatone new.htm?CYear=2015\&Vol=66\&CSubject=30\#2. Accessed 23 Feb 2017.

13. Clalit Health Services- Clalit Mushlam. Second opinion consultations (In Hebrew). https://mushlam.clalit.co.il/he/consultation/Pages/second_opinion. aspx. Accessed 23 Feb 2017.

14. Martin LT, Parker RM. Insurance expansion and health literacy. JAMA. 2011; 306(8):874-5.

15. Polinski JM, Bhandari A, Saya UY, Schneeweiss S, Shrank WH. Medicare beneficiaries' knowledge of and choices regarding Part D, 2005 to the present. J Am Geriatr Soc. 2010;58(5):950-66. 
16. Frank RG, Zeckhauser RJ. Health insurance exchanges—-making the markets work. N Engl J Med. 2009;361(12):1135-7.

17. Davidson BN, Sofaer S, Gertler P. Consumer information and biased selection in the demand for coverage supplementing Medicare. Soc Sci Med. 1992;34(9):1023-34.

18. Baron-Epel O, Balin L, Daniely Z, Eidelman S. Validation of a Hebrew health literacy test. Patient Educ Couns. 2007;67(1):235-9.

19. McCormack L, Bann C, Uhrig J, Berkman N, Rudd R. Health insurance literacy of older adults. J Consum Aff. 2009:43(2):223-48.

20. Lusardi A. Financial literacy: an essential tool for informed consumer choice? National Bureau of Economic Research; 2008. CFS Working Paper, No. 2008/ 19. http://www.nber.org/papers/w14084.pdf. Accessed 22 Feb 2017.

21. Paez KA, Mallery CJ, Noel H, Pugliese C, McSorley VE, Lucado JL, et al. Development of the Health Insurance Literacy Measure (HILM): conceptualizing and measuring consumer ability to choose and use private health insurance. J Health Commun. 2014;19(Supp 2):225-39.

22. Costa-Font J, Font-Vilalta M. Preference for National Health Service use and the demand for private health insurance in Spain, Geneva Papers on Risk and Insurance- Issues and Practice. 2004. p. 705-18.

23. Morgan RO, Teal CR, Hasche JC, Petersen LA, Byrne MM, Paterniti DA, Virnig BA. Does poorer familiarity with Medicare translate into worse access to health care? J Am Geriatr Soc. 2008:56(11):2053-60.

Submit your next manuscript to BioMed Central and we will help you at every step:

- We accept pre-submission inquiries

- Our selector tool helps you to find the most relevant journal

- We provide round the clock customer support

- Convenient online submission

- Thorough peer review

- Inclusion in PubMed and all major indexing services

- Maximum visibility for your research

Submit your manuscript at www.biomedcentral.com/submit
Biomed Central 